\title{
Explosive Power and Muscle Flexibility in Junior Gymnasts of Aerobic Gymnastic Based on Different Sexes
}

\author{
Ratna Budiarti ${ }^{1},{ }^{*}$ Siswantoyo Siswantoyo ${ }^{1}$, Endang Rini Sukamti ${ }^{1}$ \\ ${ }^{I}$ Faculty of Sport Sciences, Universitas Negeri Yogyakarta, Yogyakarta, Indonesia \\ *Corresponding author.Email: ratnabudiarti.2020@student.uny.ac.id
}

\begin{abstract}
The primary purpose of this study was to compare the explosive power ability and muscle flexibility in junior gymnasts of aerobic gymnastics based on different sexes. The data of this study were taken from 52 junior gymnasts of aerobic gymnastics from two groups consisted 26 boys and 26 girls aged 7-8 years who participated as research samples. All participants did a flexibility test using a side split test instrument and explosive power measurement using a vertical jump test instrument-the assessment of normality distribution using the Kolmogorov Smirnov test (Sig > 0.05). Furthermore, to determine the differences between the two groups, the researchers used the Independent two-sample t-test with a significance level of $p<0.05$. The side split test results showed $13.92 \pm 3.236 \mathrm{~cm}$ for the male group and $11.46 \pm 3.252 \mathrm{~cm}$ for the female group (mean $\pm \mathrm{SD}$ ) with a P-Value of 0.009 , means that there was a significant difference between the two groups. At the same time, the comparison of vertical jumps recordings also showed a significant difference with $21.12 \pm 3.514 \mathrm{~cm}$ for male groups and $18.50 \pm 5.233 \mathrm{~cm}$ for the female group (mean $\pm \mathrm{SD}$ ), with a P-Value of 0.039 . Thus, this study concluded that female junior gymnasts have better flexibility compared to male junior gymnasts. Meanwhile, the explosive power ability possessed by male junior gymnasts is better than female junior gymnasts.
\end{abstract}

Keywords: Aerobic gymnastic, Flexibility, Explosive power, Sexes

\section{INTRODUCTION}

Many studies have been conducted with aims to compare physical performances and identify talents based on sex differences [1-3]. According to [4], the success in training and talent development programs depends entirely on a clear understanding of specific performance requirements in different kinds of sports, especially those that require high flexibility and explosive power, such as aerobic gymnastics.

The term explosive power can be defined as an instantly exerted maximum muscle contraction skill carried out in an explosive burst of motion [5]. Explosive power is essential in determining many successes in many sports [6] such as aerobic gymnastics, is constructed by two physical components, including speed and strength [7].

In addition, flexibility is also an important issue as a parameter for performances in aerobic gymnastics $[5,6,7]$. Flexibility is the ability of the body to carry out the broadest range of motion in the joint space and is supported by and dependent on the elasticity of muscles, tendons, and ligaments [11]. Muscle elasticity can be increased through stretching exercises as well as training that involves the strength component. Unfortunately, many coaches think that flexibility training is enough just by doing a warming up at the beginning of the exercise [12]. Meanwhile, the fact states that flexibility exercises are highly needed to be done regularly in aerobic gymnastics, especially among young children, to help prevent injury. Flexibility can also be described as muscle flexibility in the absolute range of motion in joints or a series of joints and muscles length that cross the joint to induce movements [13] in aerobic gymnastics.

Generally, the characteristics of a people's physical condition are varied, and many factors influence it, including sex differences [4,14]. Comparing male and female players can be a good reference or an evaluation material to improve the athletes' physical conditions so that appropriate exercises can be created to improve their physical performances and achievement [15]. The comparison also can be utilized as evaluation materials to create appropriate training programs for male and female junior gymnasts.

A study conducted by Courel-Ibáñez \& HerreraGálvez [15] about a comparison of physical conditions 
based on sex differences on paddle players shows that male players have good levels of cardiorespiratory fitness, upper body strength, grip strength, speed, and agility than those female players. However, the results of dynamic balance test results on male players showed lower posterior and anterior scores than the females' results. Another study on paddle sports which was also conducted by [16], showed that female athletes have higher levels of physical fitness due to their better body balance, explosive power, abdominal endurance, and cardiovascular capacity. Furthermore, female players obtained lower waist and hip circumferences and thigh skinfold thickness compared to non-athlete subjects.

Explosive power and flexibility are two crucial factors in gymnast performances. Marefat et al. [13], in their evaluation on explosive power and flexibility based on the level of artistic gymnastics athlete status, state that explosive power and flexibility test records differed significantly between the three groups $(\mathrm{P}<$ 0,001).

On the whole, according to the literature review results, studies comparing explosive power and flexibility specifically in young aerobic gymnastics based on sex differences are still few in number. Thus, this study attempted to elucidate the potential effects of training specifications on explosive power and muscle flexibility for junior gymnasts of aerobic gymnastics based on sex differences. In other words, the subjects of this study were indifferent sex groups but at the same junior age in aerobic gymnastics. Therefore, this study aimed to study the possible effects of training specificity on explosive power and muscle flexibility in junior gymnasts of aerobic gymnastics based on sex differences

\section{METHODS}

The analysis was carried out on the data collected using a series of tests.

\subsection{Participants}

In this study, 52 junior gymnasts of aerobic gymnastics in the Special Region of Yogyakarta (male, $n=26$, female $n=26$ ) aged $7-8$ years took part as research samples.

\subsection{Procedures.}

First of all, the researchers determined the samples by taking 52 junior gymnasts of aerobic gymnastics in the Special Region of Yogyakarta. Half of them were 26 females, and the other half were 26 males of junior gymnasts of aerobic gymnastics.

Then, the researchers determined the appropriate test instrument that suited the study objectives. The instruments consisted of (1) Side Split Test to measure flexibility and (2) Vertical Jump Test to measure explosive power.

Furthermore, the researchers collected the data for the study from the junior gymnast using the Side Split Test and Vertical Jump Test.

Finally, after all of the data needed were collected, the researchers processed the data and analyzed it before drawing a conclusion from the test results.

\subsection{Measurement}

The subjects in this study were involved in a series of tests for measuring their explosive powers and flexibilities using the following test instruments (1) Side Split Test.VSide split test [17] aims to measure flexibility in the limbs. The data of this test were recorded in centimeter $(\mathrm{cm})$. The Adductor flexibility (side split) was carried out by the participants by performing the side split with their feet pointing up, their pelvis and their knees straight, and their thighs rotated outside (exercise \#16 in Alter, 2004). If the test results show a number that is closer to the floor, it means that the value of flexibility is good. In other words, it can be said that the closer the value to the floor, the better the flexibility that the gymnasts gave [18]. (2) A vertical Jump is a fitness test commonly done to determine an athlete's leg muscle strength or explosive power [19]. This test is often used by professional athletes, primarily to determine an athlete's progress during training. The higher the jump, the stronger the leg muscles/explosive power of an athlete. The result of the jump is recorded in $\mathrm{cm}$. The subjects were given two chances to do it, and the best result will be used as the final result for further statistical analysis.

\subsection{Data Analysis}

The data analysis technique in this study consisted of quantitative data analysis with arithmetic average, standard deviation, maximum and minimum data for each variable, and the assessment of normality distribution using the Kolmogorov Smirnov test (Sig > 0.05). Then to determine the difference between groups, the researchers used the Independent twosample t-test with a significance level of $\mathrm{p}<0.05$. 


\section{RESULTS}

Table 1. Results for Explosive Power and Flexibility Tests.

\begin{tabular}{|l|l|c|c|l|l|r|}
\hline I & & Mean & SD & Min & Max & P-Value \\
\hline Split (cm) & Male & 13.92 & 3.236 & 8 & 20 & \multirow{2}{*}{0.009} \\
\hline & Female & 11.46 & 3.252 & 6 & 19 & \\
\hline $\begin{array}{l}\text { Vertical } \\
\text { Jump }(\mathrm{cm})\end{array}$ & Male & 21.12 & 3.514 & 14 & 27 & \multirow{2}{*}{0.039} \\
\cline { 1 - 5 } & Female & 18.50 & 5.233 & 9 & 27 & \\
\hline
\end{tabular}

The side split test measurements showed a significant difference between the male and female groups (mean $\pm \mathrm{SD} /$ Standard Deviasion) of $13.92 \pm 3.236$ vs. $11.46 \pm 3.252 \mathrm{~cm}$ with a P-Value of 0.009 . The data provided in table 1 show that the minimum value of the two groups is $6 \mathrm{~cm}$, which we can call the best value from the split test assessment. Meanwhile, the lowest value seen in the maximum column shows a result of $20 \mathrm{~cm}$. The findings show a significant difference in the split indicator between the two sexes, male and female, because of the sig. $<0.05$. Based on table 1, females are significantly more flexible than men.

The comparison among vertical jump records also showed a significant difference between the two groups, male vs. female (mean \pm SD) of $21.12 \pm 3.514$ vs. $18.50 \pm 5.233 \mathrm{~cm}$ with a P-Value of 0.039 . This finding shows a significant difference in the vertical jump indicator between the male and female junior gymnasts because of the sig. $<0.05$. We can see in table 1 that the maximum value of the two groups is $27 \mathrm{~cm}$, which we can call the best value from the vertical jump assessment, and the lowest value can be seen in the minimum column with a result of $9 \mathrm{~cm}$. Based on table 1, male junior gymnasts have significantly more explosive power than female junior gymnasts

\section{DISCUSSION}

The study focused on the comparison of explosive power and flexibility between male and female junior gymnasts in aerobic gymnastic sport. The samples in this study were 7-8 years old gymnasts - equalization of age to minimize the effect of maturation on the gymnasts' performances. The reason for using samples in the junior category was that younger children have immature joints suitable for preparing the proper and specific exercises for junior aerobic gymnastics that require high flexibility and power.

The primary purpose of this study was to examine the characteristics of muscle flexibility and explosive power of junior gymnasts of aerobic gymnastics and determine the differences in physical performance based on their sexes. This study also evaluated the flexibility and explosive power of male and female junior gymnasts of aerobic gymnastics. Such knowledge is essential for identifying the determinants of player performances and competitive success and injury prevention in aerobic gymnastics.

Sex differences can affect a person's physical condition [20] on many sides. Even cross-sectional comparisons are difficult to interpret even if boys and girls are at the same chronological age, so varying biological ages of children and adults can result in sub-substantial differences in fitness [1]. Whereas, an understanding of sex differences in physical fitness can improve exercise programs, assessment, and comparison of physical fitness performance scores in boys and girls in the relevant age range [1].

Explosive power is an essential factor in determining success in many sports [6]. The explosive power indicators for junior gymnasts in this study were evaluated using a vertical jump test. The results showed that male junior gymnasts had significantly higher explosive power than female junior gymnasts. This result is in line with research conducted by Pradas et al. [14], which states that male players have higher explosive power values than female players. As we know, explosive power is not one component but combines two components of physical condition, namely strength, and speed. Males tend to produce greater strength and speed than females because they have enormous muscle mass. Compared to males, females have lower hemoglobin, the protein in red blood cells, which binds and carries oxygen to body tissues, including muscles. Another factor that can influence the results of the findings of this study was that the level of physical activity of males is usually more active than females [21]. These factors were the possible causes of the results of this study, saying that the explosive power possessed by males was better than females.

The results of a comparative study regarding muscle flexibility in aerobic gymnastics between male and female junior gymnasts revealed that females' muscle flexibility was better than males'. This finding was in line with several studies examining muscle flexibility based on sex differences. Tsolakis \& Bogdanis, in their research about flexibility and lower limb explosive performance based on condition, time, and sex difference, revealed that there was a significant difference in the sex variable $(\mathrm{p}<0.001)$ where females had greater flexibility as a free range of motion (ROM) compared to males [22]. Research on flexibility based on sex that has also been carried out by Apriantono et al. stated that junior female badminton athletes have better flexibility than junior male badminton athletes. $(p=0.001)$ [23].

The literature review conducted by Otsuki et al. [2] claimed that females' flexibility is better than 
males' due to several factors. The first factor includes the process decreasing blood volume when muscles are doing extension is better in females than in males. In other words, it can be said that the mechanism of blood flow in the arteries in females is better than in males [24]. The second factor is the influence of the estrogen hormone, which makes differences in muscle composition in males and females. The muscle composition of females is less than that of males, causing flexibility in females to be better than males [3]. The last factor was the fasciculations in the tendon muscles, which are better in females than in males, thus making females more ideal in doing extension movements [25].

\section{CONCLUSION}

This study shows quantitatively that in aerobic gymnastic sport, junior female gymnasts have better flexibility than junior male gymnasts. On the other side, the explosive power ability possessed by junior male gymnasts is better than junior female gymnasts. Thus, we encourage aerobic gymnastics trainers and aerobic gymnastics practitioners to design appropriate exercises based on sex characteristics and muscle abilities, especially training designs for flexibility and explosive power abilities to improve athlete performance and achieve maximum performance.

\section{REFERENCES}

[1] S.D. Flanagan, C. Dunn-Lewis, D.L. Hatfield, L.J. Distefano, M.S. Fragala, M. Shoap, M. Gotwald, J. Trail, A.L. Gomez, J.S. Volek, C. Cortis, B.A. Comstock, D.R. Hooper, T.K. Szivak, D.P. Looney, W.H. Dupont, D.M. McDermott, M.C. Gaudiose, W.J. Kraemer, "Developmental differences between boys and girls result in sex-specific physical fitness changes from fourth to fifth grade," J. Strength Cond. Res, (2015). https://doi.org/10.1519/JSC.0000000000000623.

[2] A. Otsuki, Y. Muraoka, E. Fujita, S. Kubo, M. Yoshida, Y. Komuro, S. Ikegawa, Y. Ohta, M. Kuno-Mizumura, "Gender differences in muscle blood volume reduction in the tibialis anterior muscle during passive plantarflexion," Clin. Physiol. Funct. Imaging (2016) 421-425. DOI: https://doi.org/10.1111/cpf.12232.

[3] C.I. Morse, "Gender differences in the passive stiffness of the human gastrocnemius muscle during stretch", Eur. J. Appl. $\begin{array}{llll}\text { Physiol. } & 111 & (2011) & 2149-2154 .\end{array}$ https://doi.org/10.1007/s00421-011-1845-z.

[4] T.O. Bompa, Theory and Methodol of Training, Kendall/Hunt Publishing Company, 2012.

[5] T.O. Bompa, M. Carrera, Conditioning young athletes, Human Kinetics, 2015.

[6] J. Fernandez-Fernandez, A. Ulbricht, A. Ferrauti, "Fitness testing of tennis players: How valuable is it," Br. J. Sports Med. (2014). DOI: https://doi.org/10.1136/bjsports-2013093152.

[7] T.O. Bompa, C. Buzzichelli, Periodization-: theory and methodology of training, Human kinetics, 2019.

[8] R.E. Thomas, B.C. Thomas, "A systematic review of injuries in gymnastics," Phys. Sportsmed. 47 (2019) 96-121. DOI: https://doi.org/10.1080/00913847.2018.1527646.
[9] A. Bota, C. Urzeală, "Correlative Aspects Regarding Functional Stress and Neuromuscular Control in High Performance Aerobic Gymnastics - Individual Events," Procedia - Soc. Behav. Sci. 93 (2013) 2090-2094. DOI: https://doi.org/10.1016/j.sbspro.2013.10.171.

[10] M. Mariana, C. Orlando, "Performance Criteria in Aerobic Gymnastics - Impact on the Sportive Training," Procedia Soc. Behav. Sci. 117 (2014) 367-373. DOI: https://doi.org/10.1016/j.sbspro.2014.02.229.

[11] D.G. Behm, A. Chaouachi, "A review of the acute effects of static and dynamic stretching on performance," Eur. J. Appl. $\begin{array}{llll}\text { Physiol. } & 111 & \text { (2011) 2633-2651. } & \text { DOI: }\end{array}$ https://doi.org/10.1007/s00421-011-1879-2.

[12] G. NICULESCU, E. SABĂU, D.I. LĂCĂTUŞ, "Study on the Use of Static Strength Elements in the Performance Aerobic Gymnastics," Bull. Transilv. Univ. Braşov. 4 (2011) 149-153.

[13] S. Marefat, B.M. Ebrahim, M. Mehdi, "Muscle flexibility and explosive power in young artistic gymnast boys at different performance level," Sci. Gymnast. J. 13 (2021) 253-262. DOI: https://doi.org/10.52165/sgj.13.2.253-262.

[14] F. Pradas, A. Sánchez-Pay, D. Muñoz, B.J. Sánchez-Alcaraz, "Gender differences in physical fitness characteristics in professional padel players," Int. J. Environ. Res. Public Health. 18 (2021). https://doi.org/10.3390/ijerph18115967.

[15] J. Courel-Ibáñez, J.J. Herrera-Gálvez, "Fitness testing in padel: Performance differences according to players' competitive level," Sci. Sport. 35 (2020) e11-e19. DOI: https://doi.org/10.1016/j.scispo.2019.05.009.

[16] J. Courel-Ibáñez, J.C. Cordero, D. Muñoz, B.J. SánchezAlcaraz, F.J. Grijota, M.C. Robles, "Fitness benefits of padel practice in middle-aged adult women," Sci. Sport. 33 (2018) 291-298. DOI: https://doi.org/10.1016/j.scispo.2018.01.011.

[17] M.J. Alter, Science of flexibility, Human Kinetics, 2004.

[18] A. Guillot, C. Tolleron, C. Collet, "Does motor imagery enhance stretching and flexibility?," J. Sports Sci. 28 (2010) 291-298. DOI: https://doi.org/10.1080/02640410903473828.

[19] M. Alp, B. Gorur, "Comparison of Explosive Strength and Anaerobic Power Performance of Taekwondo and Karate Athletes," J. Educ. Learn. 9 (2020) 149. DOI: https://doi.org/10.5539/jel.v9n1p149.

[20] J.K. Nelson, J.R. Thomas, K.R. Nelson, P.C. Abraham, "Gender differences in children's throwing performance: Biology and environment," Res. Q. Exerc. Sport. 57 (1986) 280-287. https://doi.org/10.1080/02701367.1986.10608088.

[21] J. Mota, P. Silva, M.P. Santos, J.C. Ribeiro, J. Oliveira, J.A. Duarte, "Physical activity and school recess time: Differences between the sexes and the relationship between children's playground physical activity and habitual physical activity," J. Sports Sci. $23 \quad$ (2005) 269-275. DOI: https://doi.org/10.1080/02640410410001730124.

[22] C. Tsolakis, G.C. Bogdanis, "Acute effects of two different warm-up protocols on flexibility and lower limb explosive performance in male and female high level athletes," J. Sport. Sci. Med. 11 (2012) 669-675.

[23] T. Apriantono, I. Herman, R. Syafriani, A.D. Juniarsyah, "Analisis Fleksibilitas Pada Atlet Bulutangkis Junior Indonesia Flexibility Analysis in Indonesian Junior Badminton Athletes Ilmu Keolahragaan Sekolah Farmasi Instutut Teknologi Bandung," (n.d.) 74-80. https://doi.org/https://doi.org/10.21009/JSCE.05209.

[24] B.A. Parker, S.L. Smithmyer, J.A. Pelberg, A.D. Mishkin, M.D. Herr, D.N. "Proctor, Sex differences in leg vasodilation during graded knee extensor exercise in young adults," J. Appl. Physiol. $103 \quad$ (2007) 1583-1591. DOI: https://doi.org/10.1152/japplphysiol.00662.2007.

[25] K. Kubo, H. Kanehisa, K. Azuma, M. Ishizu, S.Y. Kuno, M. Okada, T. Fukunaga, "Muscle architectural characteristics in young and elderly men and women," Int. J. Sports Med. 24 (2003) 125-130. DOI: https://doi.org/10.1055/s-2003-38204. 